\title{
Research on Teaching Method of Computer Information Management Course for Optoelectronic Engineering
}

\author{
Han Liang, Yang Wei, Cui Bin, Liu Delian \\ School of Physics and Optoelectronic Engineering, Xidian University \\ Xi'AN, 710071, P.R.China
}

\begin{abstract}
Due to some reason, the teaching effect of computer information management course of optoelectronic engineering is not ideal. Based on the characteristics of optoelectronic engineering, this paper proposes a teaching method of computer information management course based on interest drive. This course has achieved good teaching results by cultivating students' points of interest, designing tasks based on a large amount of data from optoelectronic projects, and stimulating incentives for interest, Improving the enthusiasm and motivation of students to learn computer information management.
\end{abstract}

Keywords-optoelectronic engineering; computer information management; interest-driven; task

\section{INTRODUCTION}

With the development of information technology in recent years, the era of "big data" has come. The data has become a valuable asset, and computer information management as the basis of data applications has become increasingly important. However, over the years the training of computer information management skills is not enough for optoelectronic engineering students as result of focusing on the cultivation of mathematical and physical skills. Some problems exist in the teaching process of computer information management [1].

Firstly, the most of students doesn't understand the importance of computer information management knowledge and skill and doesn't realize the close connection between optoelectronics and computer information management.

Secondly, students do not spend much time on the course, they usually just come to class and go. They don't review effectively after class so as to the bad learning effect.

Thirdly, the teaching of computer information management course over the years is often focused on theoretical knowledge. Teacher usually can not pay attention to the interest of students in this class in the new era so that the course is thought dull and unattractive to students.

Finally, the interest of students can not be developed adequately because the traditional teaching mode can be summarized as "a pot of chaos' . The teaching contents and the curriculum guidance methods for the students are the same.
The examination form is simply written on paper, which makes the personal interest can't play. Under this unitary assessment, Individual strengths can not be developed and evaluated so that students gradually lose confidence and interest and the teaching effect will be greatly reduced.

With the development of various data in optoelectronic engineering, it is very urgent for graduates to master computer information management ability. Based on the characteristics of optoelectronic engineering, this paper puts forward the method based on interest for the teaching of computer information management course in order to make students have good computer information management ability for the challenge in the "big era".

\section{INTEREST-DRIVEN TEACHING METHODS OF COMPUTER INFORMATION MANAGEMENT}

\section{A. The discovery of interest}

Interest is a kind of psychological tendency of seeking to know or engaging in a certain kind of activity. Students who are interested in certain things are willing to touch and observe that and actively try hard to reveal the mystery on that [2-3]. For example at present the hot spots that students pay attention to are directly or indirectly derived from the Internet. The hot spots on the Internet always change rapidly one after another. Along with the implementation of China's Internet plus strategy, the Internet and daily life must be closer and closer with each other. It gives us a thought that the computer information management teaching should be linked to the hot spots on network. Teacher can make use of the hot spots on network and analyze what kind of role that the computer information management technology plays behind the hot spots. It can not only motivate the interest of student to learn computer information management technology but also enhance their cognition of the importance of this course.

Hence, teacher also can use this kind way to inspire the interest of students to the application of computer information management technology in optoelectronic engineering. It inevitably requires teacher not only to know well about the current tendency of computer information management 
technology in optoelectronic engineering but also to be aware of what students care about. Teacher should figure out the connection between them. For example, nowadays the competition is very intensive and students have already noticed it. They always feel anxious in varied degree about their future. Teacher can grasp this point and make use of his professional knowledge to inspire the interest of students in the course and help them using this technology to sort out the big information about optoelectronic engineering. It can motivate students to learn this course on purpose [4].

Teachers should inspire the interest of student [5] and know well about what kind of the knowledge and experience that their students have. They should tap the students' interests and combine teaching content with the network hot spots. Teacher should play their own creativity and teaching characteristics and charm to infect students. They can infuse the abstract knowledge into the vivid image of the classroom teaching activities to create a specific teaching situation, stimulate students from the strong interest. They should help students to open the new gate of thinking in order to make them into a realm named "I want to explore" and develop the motive force of learning independently.

\section{B. The cultivation of interest}

The key to make the study of computer information management sustainable and have the virtuous circle of learning the course is to make students feel useful for learning computer information management. This availability doesn't not only refer to the daily Life but also refer to the personal development all their life. The knowledge can be thought as mastered one by students till it can be applied into practice. That kind of knowledge is the one that is interesting to students. By the method, we can make students pay more attention to this course learning.

After students are interested in the course learning, they can fully play to their own ability of autonomous learning. Students can obtain information to think through the Internet. At the same time, the learning atmosphere in the classroom also can be changed. Teacher can bring the main role of the students in classroom into full play and help students analyze the problem that they can not solve. Teacher should consolidate and deepen the understanding of the concept, mobilize the enthusiasm of students to explore so that students take the initiative to acquire knowledge and apply knowledge to solve the practical problem. It will make students step by step into the problem-driven stage and ultimately find a solution to cultivate student's interest.

It can be a long way for students to maintain the learning interest. The key for that is to make students have a beginning and an end, perseverance, which is also an important aspect for each teacher to cultivate students. If students can learn, know how to learn, love to learn, they have laid a solid foundation for the study of knowledge. However, due to the change of students' interest and lack of perseverance, Teacher should encourage them and intends to correctly guide in order to maintain students interest in computer information management for a long time.

\section{IMPLEMENTATION OF COMPUTER INFORMATION MANAGEMENT TEACHING BASED ON INTEREST}

\section{A. The task of interest enhancement}

The study of modern psychology shows that by giving students a difficult task in certain degree, it can make studentinitiated learning as well as finishing the task, which can greatly improve the sense of achievement and strengthened interest of students [6-7]. To implement interest-driven computer information management teaching needs to design tasks according to student acceptance ability so that students can learn in the task. The corresponding data with the development of photovoltaic technology in recent years is also greatly increased. Therefore, Teacher can design some tasks related to practical needs of optoelectronic engineering data management and require students to find some solutions to finish the tasks independently [8].

Hence, the author has made some interest-driven tasks derived from the past scientific research projects related to optoelectronic engineering data and some practical needs for students. In the past decade, the author and his group has undertaken a number of domestic optoelectronic database management project outsourced from engineering research institute and accumulated a lot of raw data, which can easily design a lot of different difficulty of the tasks for students.

Here is an example for the construction of typical tasks using the usual optoelectronic engineering data. Optoelectronic engineering data is mainly Graphic data, video data, etc. Graphical data generally refers to some simple regular geometric. Image data refers to a still picture. The video data refers to a moving image made of a series of still images, and a series of Time-varying media. The general video data also contains audio graphics or text and other video data. So how to classify the optoelectronic data and model the abstraction of these data, how to design data tables and fields, How to build a small database and so on can be decomposed a series of tasks for the entire teaching process.

The interest driven teaching mode reform is to improve students' application ability. The application ability is decided by the social demand of the talent market. So the task should be set to be practical. On the one hand, it is related to the major, activating the thinking of students and improving their interest; on the other hand, the practicability enables students to study the content of social needs and greatly improves their ability to work after graduation. Therefore, in designing tasks, we should consider the combination of practicability and knowledge.

The natural process of learning the knowledge is step by step. Teacher should pay attention to this process. Hence, when teachers design some tasks for students, they should sort out the relevant connection between knowledge points, practical skills of computer information management. The task for students should be from easy one to difficult one, step by step. The early ones should be as much simple and practical as possible and then slowly added difficulty. It can not only make students master the knowledge imperceptibly in learning but also will not start to feel that learning is very difficult and lose confidence and interest in learning. 


\section{B. The completion of task}

The interest driven teaching model takes the students as the main body and the teachers as the leading role as following figure 1.

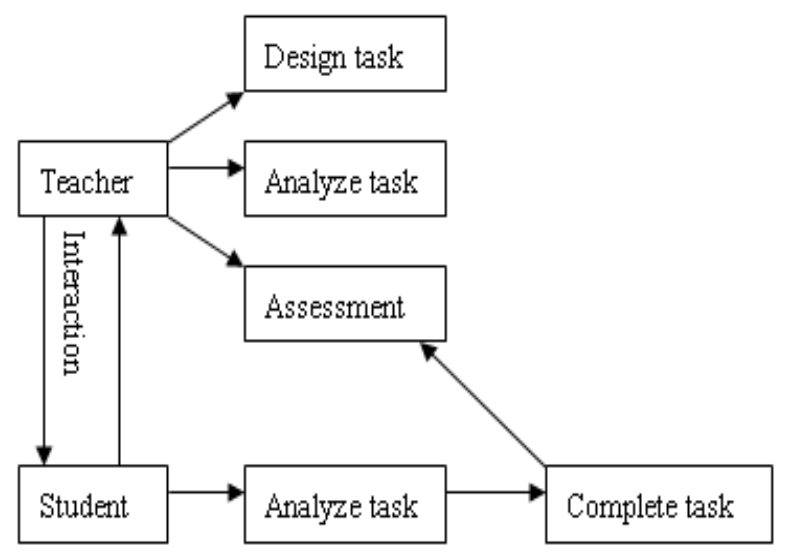

Fig. 1 The completion of task

To complete the task, teachers can first give a brief analysis of the task. Teacher should point out the emphasis and difficulties of learning and related content of the completion of the task. In the process, teacher should give way to guide with the "black box" type of thinking, which means the beginning and the end of the task is only given but the middle ignored. Instead of imprisoned thinking, by this way students can have a process of understanding the tasks and teacher also can make the necessary hints or needs for them.

In the process of students' tasks, students should be encouraged to interact with each other. If the task is difficult for a student to complete independently, teacher can divide them into many groups and encourage them to collaborate with each other. The interaction between teachers and students is also important. Teacher can timely detect problems and give the guidance for common problems that happen in the process of task. Teacher also can be conscious of psychological tendency of the students to this task by the interaction. If the most of students lose the interest of the task, teacher can adjust the content or difficulty on the next task. Teachers and students should be on an equal footing and solve problems in the teaching process at any time. Teacher also should listen to the opinions and suggestions of the students. In short through exchanges and cooperation, enthusiasm and self-confidence of learning can be greatly stimulated and the interest driven teaching effect can be enhanced.

After each phase of the task is completed, the students are organized to discuss their gains and losses, and to summarize their accomplishment and reasons. At the same time the public display of all works, and discuss the advantages and the work to be improved, and some good works compare, the key content of this lesson can be further strengthened, also can cultivate students' sense of achievement, to further stimulate the enthusiasm of students learning, to maintain a strong interest in learning, produce strong learning motivation on subsequent learning task. The whole process to maintain a relaxed and pleasant atmosphere, make students keenly aware of the joy of learning. Teachers should pay attention to protect students' self-esteem and self-confidence, fully affirm the advantages and encourage the use of encouraging language, so as to maintain their good learning momentum. The evaluation result is included in the student's examination results.

The sense of interest and the sense of achievement are important in the interest driven teaching mode of computer information management. The task should be designed to stimulate students' interest in learning as a starting point and to meet the students' desire to explore as a subjective desire in order to complete the teaching task as the ultimate goal. Subjective desire and ultimate goal are the unity of mutual restriction. Any mistakes in the course will make the classroom teaching fail. In the interest driven model of teaching, students will get a successful experience and learning enthusiasm unprecedented form each completed task. In this way, students can not only master the knowledge and skills, but also can flexibly use the knowledge and skills to complete the tasks of the actual work and life while improving their interest in learning. As each task has innovative content and innovative incentives, so students are trying to create more distinctive results, thereby greatly developing the personality of students, to comply with the requirements of future career.

\section{Course assessment}

The assessment of traditional computer information management courses are mainly based on closed-book examination and the usual performance as a supplement. In recent years with the computer application as a necessary skill for college graduates, computer practice has become increasingly important. So the assessment of the computer information management pays more attention to the practical ability of students. In other words, teacher should focus on the actual ability of students in the usual performance. The evaluation includes the evaluation and test of the student's completion of the task. The total term of the semester includes both the usual grade and the test result. The usual grade is the usual performance of the student, the completion of the task on the computer, the overall completion of the task, class participation. The above mentioned four parts account for half of the total score; test scores at the end of the semester are the results of the examination, which accounts for half of the total score. In addition, the test paper content is not only focused on theoretical knowledge assessment. The theoretical, memory content of the assessment has been reduced and the comprehensive application of the assessment has been increased in the paper test.

\section{CONCLUSION}

Through the two years of experiment on the computer information management course of optoelectronic engineering, the students' computer information management ability has been greatly improved. A group of students have been funded by national innovation project of the computer information management application. Through the author's post-class survey, it has been found that interest-driven teaching methods can significantly improve the students' subjective initiative and improve the computer information management courses learning effect as well as enhance the computer skills of 
students, which is of good significance for the employability of students.

\section{REFERENCES}

[1] Wang Yali, Han Weiyuan. Reflections on the Reform of Computer Information Management Specialty in Higher Vocational EducationExploring [J]. Education and Career, 2012,30: 114-116.(in Chinese)

[2] Shen Bo, Chen Ang, Guan Jianmin and interest to predict learning in physical education [J]. Journal of Experimental Education. 2007, 75 (2): 89-108.

[3] Guo Ge. On the principles of interest teaching thinking [J]. Educational research,2012, 03: 119-124. (in Chinese)
[4] Zheng Kaitao. Exploration of task driven teaching model[J]. Forum on ContemporaryEducation, 2008,8:116.

[5] Zhao Lanlan, Wang Ling.Study on the study of learning interest [J] .Journal of Capital Normal UniversityScience Edition), 2006,06: 107112. (in Chinese)

[6] Li Zhanxuan. Task-driven teaching method in the database teaching application [J]. EducationCable, 2010, (12): 52-53. (in Chinese)

[7] Yue Shu Ling. Task-driven method in SQLServer database management teaching Application [J]. Education and Career, 2013,20: 149-150. (in Chinese)

[8] $\mathrm{H}$ a kan Fleischer.What is our current understanding of one-to-one computer projects: A systematic narrative research review[J] .Educational Research Review, 2012, 7: 107-122. 